Article

\title{
A Demand-Side Approach for Linking the Past to Future Urban-Rural Development
}

\author{
Schuman Lam*, Heng Li and Ann T. W. Yu \\ Department of Building and Real Estate, The Hong Kong Polytechnic University, 852 Hong Kong, China; \\ E-Mails: schuman.sm.lam@connect.polyu.hk (S.L.), heng.li@polyu.edu.hk (H.L.), ann.yu@polyu.edu.hk (A.T.W.Y.) \\ * Corresponding author
}

Submitted: 30 October 2020 | Accepted: 8 February 2021 | Published: 25 May 2021

\begin{abstract}
Is economy-led urbanization the only answer to urban planning? By 2050 , about $70 \%$ of the world population will live in urban areas, intensified by rapid urbanization in developing countries. A new urban development framework is critically relevant to investigating urban living's emerging complexity for advancing human-social-economic-environmental sustainability. The multi-disciplinary study explores a roadmap for solving industrialization's adverse effects to inform future resilient development in developing countries. The classical Maslow's Hierarchy of Needs (MHN) and some scholars have stated that human physiological needs would be prioritized and fulfilled by developing countries, and psychological needs would be satisfied and desired by developed countries after fulfilling physiological needs level. Our study argued that transitoriented-development (TOD) and ICT could simultaneously fulfill some essential physio-psychological needs with digitalruralism. Structural equation modeling (SEM) was adopted to test the indicator-based MHN theory developed by literature, urban quality of life (Uqol) evaluation between the developing and developed countries, and backed by digital-ruralism success in developing China. The Uqol evaluation identifies the developing countries' subjective well-being demand as the health, mobility, governance, environment, social, economy, human capital, technology-ICT, smart living, and lifestyle, which are used to transform the classical MHN model to the indicator-based MHN model. The SEM subsequently illustrates that the observed well-being indicators are positively correlated to the TOD and ICT, defined by the proposed urbanruralism development framework. The study contributes to an innovative approach to reconnect the classical MHN theory to contemporary sustainable urban planning while narrowing the socioeconomic-environmental gap between the developed (urban) and developing (rural) domains, which encourages a paradigm shift for future resilient urban development in the developing countries.
\end{abstract}

\section{Keywords}

digital-ruralism; Maslow's Hierarchy of Needs; post-industrial development; quality of life; resiliency; sustainable urban development

Issue

This article is part of the issue "Planning for Rapid Change in Cities" edited by Karina Landman (University of Pretoria, South Africa).

(C) 2021 by the authors; licensee Cogitatio (Lisbon, Portugal). This article is licensed under a Creative Commons Attribution 4.0 International License (CC BY).

\section{Introduction}

In the past and now, the city is the heart of global power where economic, cultural, social, and political centers locate. It has since remained a major attraction and triggered human migration and dislocation, mainly for job opportunities. City development dictates the ways of human living and the fabrication of our natural landscape. Although urbanization provides employment, social living, and urban lifestyle to urbanites, the rosy picture of urbanization driven by economy-led urbanism is responsible for $80 \%$ of the world's resource consumption. Many urban problems such as crime, mental health, homelessness, an influx of immigrates, unemployment, 
poverty, pollutions, and planetary problems, including climate change, ecological degradation, biodiversity loss, result in lower quality of life (QOL). These current challenges for cities' sustainability goals have been highlighted and discussed on the global agenda for work (CIMI, 2018).

Rapid urbanization led by the first and second industrial revolutions has shaped the urban landscape in developed countries and some parts of the world's developing regions. United Nations predicted that three out of four people will habitat, live, work, or commute to work in the urban area in the future. Although globalization's trend fosters economic growth and urban development, it undermines social and environmental sustainability because of overexploitation on our labor and natural resources and the misuse of capital, which disrupts the balance of sustainability and degrades people's QOL. For example, the manufacturing towns and cities, such as Pittsburgh (USA), Detroit (USA), Wakefield (UK), Burnley (UK), and Mirafiori (Italy), have been hurt by high social deprivation and job loss, and Dongguan city and many other industrial towns in developing China have gone through the same historical setbacks. They need effective revitalization plans to tackle the pressing socialeconomic-environmental-cultural issues and to ease the development gaps between the densely populated city center and the marginalized countryside, especially the pleas for solutions at the local level. Therefore, we should rethink the conventional economy-led urban development strategy and search for a better path to build our future habitat.

Indeed, economic growth is essential for improving livability. However, limited natural resources fix the scheme of social, economic, and environmental sustainability. Premised by the rule of demand and supply, a notion of growth and development based on equilibrium becomes the new standard for optimization and sustainability. Speedy urbanization in the developing world signifies that matching urban resources (supply) and QOL needs (demand) is crucial for future regional and global sustainable growth (Park, 2017). How well governments can allocate their resources to build a sustainable habitat and improve their citizens' living environment becomes overly critical in urban policymaking and planning; in return, the citizens should think and behave to support the introduced urban development policy. Their mutual understanding and cooperation are needed for realizing the sustainability scheme. Thus, investigating the residents' well-being demand is the first step for paving the feasible way for policymaking and planning.

\subsection{Digital-Ruralism Support in Developing China}

In the case of developing China, it adopted a transitICT development approach on solving its three rural issues (San Nong) relating to the agricultural industry, rural conditions, and farmers' ways of life, while combating its urban challenges. The Chinese rural develop- ment strategy relatively simulates the same DNA as the urban-rural development network of city-town-village for developing countries introduced by Rondinelli (1983). Further to follow the 2030 Agenda of the UNDP advocating to embark on a development journey leaving no one behind (UNDP, n.d.), the central government implemented digital-ruralism to narrow the well-being and digital gaps between urban and rural areas. Transit-orienteddevelopment (TOD) and ICT development policy become the primary pursuit of the central and local governments (Qiang, Rossotto, \& Kimura, 2009).

Often prioritized by the developing countries in the beginning stage of urban development, TOD is for economic development first and foremost. In 1978, infrastructure started to develop China when $90 \%$ of Chinese work in the countryside. During the industrialization period, many youngsters moved to the city for better job opportunities and living standards. The rural residents are mainly aged farmers with low income and education because they are physically isolated from the marketplace and urban areas. Since then, the high-speed railway network has been rapidly built to cover the whole country, from the well-developed capital city Beijing to the less developed landlocked region Ningxia to different China's major cities for logistic support and improving liveability. So far, 35,000 kilometers of the high-speed rail network has been built, exceeding the rest of the world's total length combined ("From nobody to somebody," 2020). It speeds up the urbanization process substantially while facing similar setbacks as the developed countries, such as the unsustainable living environment in the densely populated city center, marginalized postindustrial cities and towns, and run-down rural areas. Thus, the central government introduced the ICT-driven digital-ruralism development policy two decades ago. It has since attracted a handful of urbanites moving back to the countryside to operate e-business and work in tourism industries besides farming.

China modified the action-based ICT eEurope 2005 and i2010 development frameworks addressing its county and local village conditions in terms of demographic, economic, cultural, and political backgrounds to tackle the economic and digital divide between the urban and rural areas. It launched the National ICT Development strategy (2006-2010) to boost the economy and social improvement in the agriculturalbased rural areas, installing ICT-enabled hardware and establishing ICT help centers in the designated villages or counties to narrow the socioeconomic and digital gaps. The physical infrastructure, such as roads, high-speed railways, other public transportation modes, and post offices facilitated by ICT, has been built to serve consistent economic growth in remote communities. E-government, e-learning, e-health services, e-entertainment, and e-shopping make up the e-business environment in the ICT-enabled rural areas. The infrastructure enhancement, human capacity, and service enrichment provide a holistic environment to 
advance the economy, society, culture, and governance to merge the gap between urban and rural areas (Statistical Report, 2017).

By March 2020, China had 904 million netizens, and 99.3\% are mobile phone users, with a remarkable surge trend over the past years (Figure 1). Rural Internet users had 255 million occupying $28.2 \%$ of China's total netizen population, up $1.5 \%$ from 2018. Urban Internet users had dropped from $73.3 \%$ to $71.8 \%$ (649 million) of China's total netizen population (Figure 2). The total Internet user sizes' distribution was $78.6 \%$ (710 million) for e-shopping, $85.0 \%$ for e-payment, $94.1 \%$ for e-entertainment, and $76.8 \%$ for e-government services in China (Statistical Report, 2020).

Figure 3 shows the narrowing of the increase in Internet penetration rate between urban and rural areas. The popularity and accessibility of ICT in China's urban and rural areas set an extremely favorable digitalruralism development environment. According to the National Bureau of Statistics, the number of $5 \mathrm{G}$ terminal connections has exceeded 200 million, ranking first globally. However, a shortage of Internet skills, lim- ited literacy level, and an aging population were significant factors preventing non-netizens from accessing the Internet in rural areas, waiting for improvement (Statistical Report, 2020).

Nevertheless, the snowball effect triggered by ICT is unimaginable and unmeasurable. ICT favors e-business; besides, it accommodates residents' safety needs. For example, security would be an important issue in rural areas due to its low population density and remoteness; a smart living space can be furnished with artificial intelligent surveillance systems. Thus, ICT becomes one of the critical components in future urban-rural digital development, with TOD to fulfill the Maslow's Hierarchy of Needs (MHN) and impact society (Freeman, 1996). With such progressive digital-ruralism support in developing China, urban location will not be a critical factor for urban migration when the fundamental physio-psychological needs can be satisfied in rural areas through digital-ruralism. Remarkably, through infrastructure development (physically and virtually), China moves most of its 1,4 billion population out of poverty in 2020 , accounting for $80 \%$ of world poverty reduction and creating the world's largest

Unit: 100 million GB

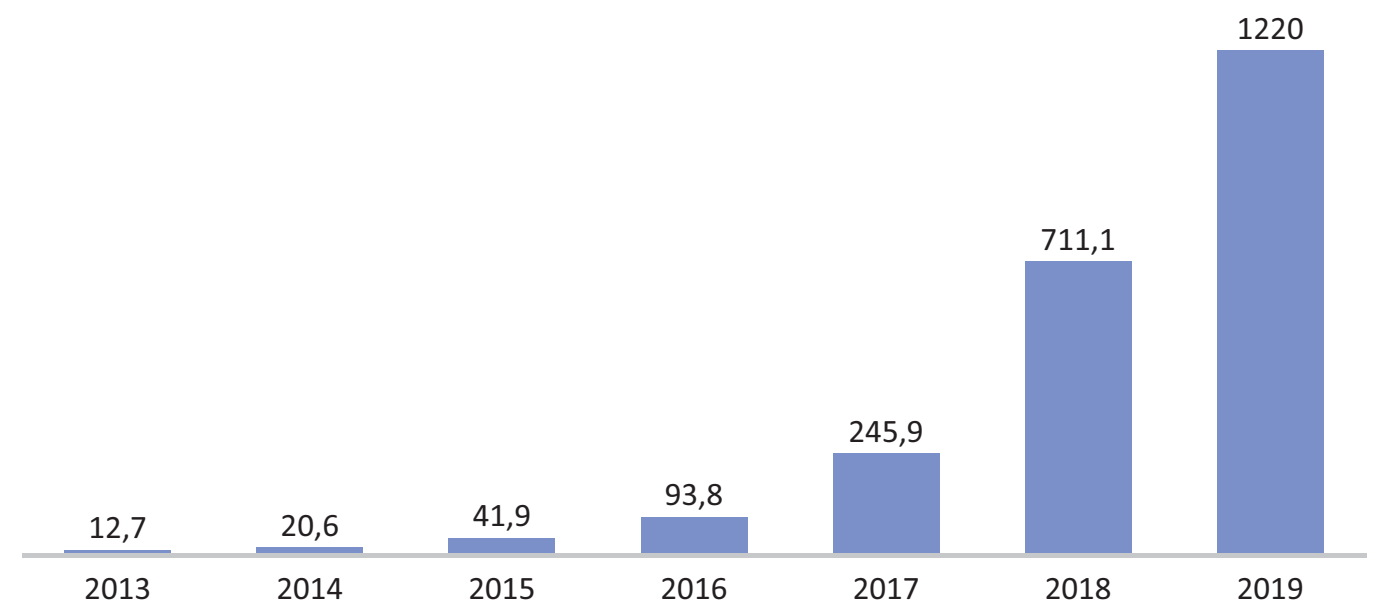

Figure 1. Mobile Internet access traffic in China. Source: Statistical Report (2020).

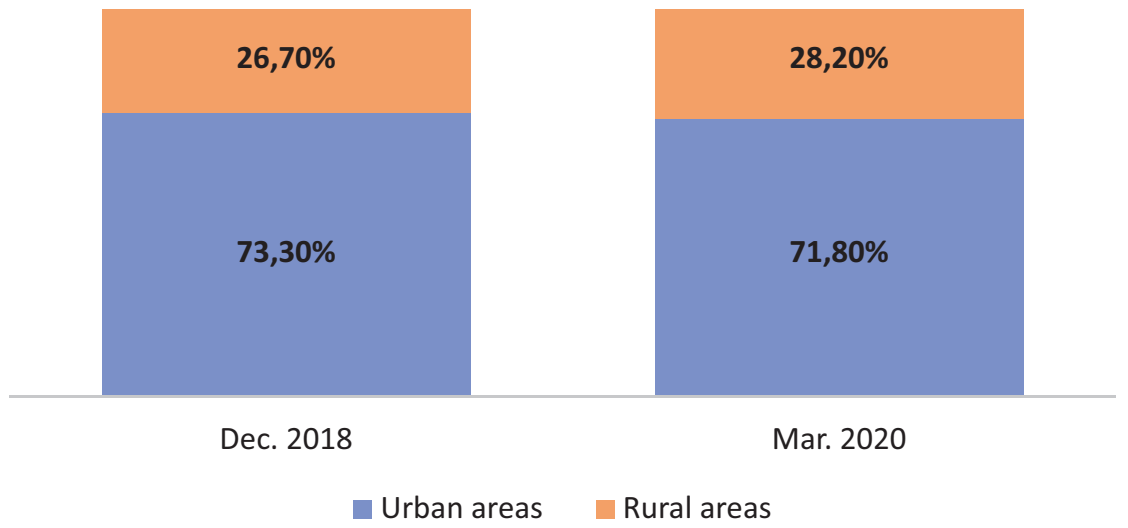

Figure 2. Urban and rural structure of Internet users. Source: Statistical Report (2020). 
- Internet Penetration in Urban Areas $\quad-$ Internet Penetration in Rural Areas

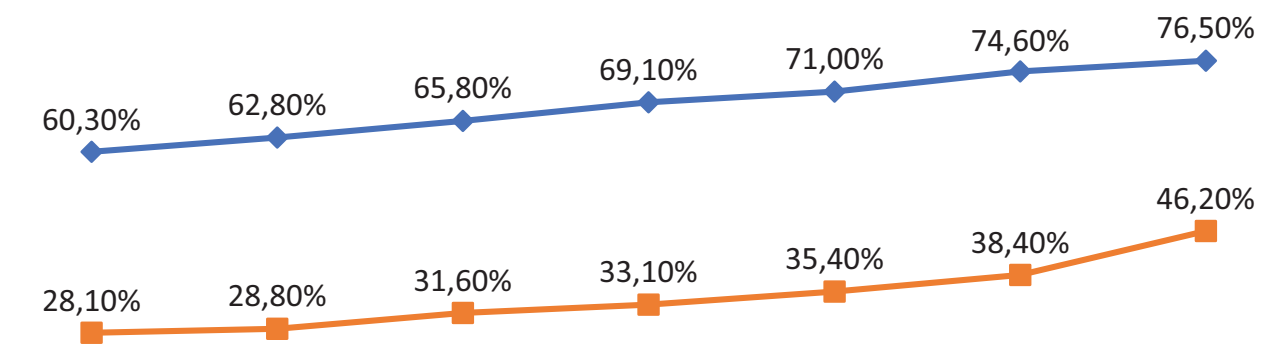

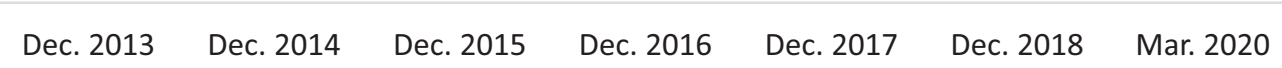

Figure 3. Internet penetration in urban and rural areas. Source: Statistical Report (2020).

middle-class per country in 2020 according to United Nations. China's digital-ruralism strengthens socioeconomic activities in remote areas and sheds light on a TOD-ICT-led urban-ruralism (UxR) development framework for the developing countries.

\subsection{Sustainable Urban Development, TOD and ICT Impacting on $\mathrm{MHN}$}

Most of us agree that QOL is a broad and vague concept, and its multitude of concepts makes it very difficult to be understood precisely and inclusively even though various definitions of QOL have been found from almost every academic discipline concerned institutions. QOL is a kaleidoscope with all these ever-evolving segments inside. Subjective well-being surveys consistently show that more equal societies contribute to the highest life satisfaction and happiness (Helliwell, Huang, \& Wang, 2019). Well-being depends upon good health, positive social relationships, and accessibility to necessary resources such as mobility and employment (Ballas \& Tranmer, 2011), more than economic satisfaction in the domain of overall life satisfaction, which has been highlighted in the urban quality of life (Uqol) evaluation (Table 1). Relevantly to the sustainable urban development (SUD) equilibrium, MHN is the different levels of motivations and human needs evolving and correlating along the city development lifecycle, which is the impetus for distributing the resource and labor equitably and sustainably, disregarding the external factors. MHN is the alpha principle, vaulted by the humanphysical-contextual environment, the powerful synthesizer upholding all the relevant disciplines contributing to the overall QOL. Often, the MHN basic physiological need level is most likely acquired by the developing countries' pre-requisite for an upgrade of the higher psychological need level to catch up with the developed countries (Maslow, 1943). What if TOD and ICT can serve the two $\mathrm{MHN}$ levels altogether? The well-being gaps between the developing and developed countries or the urban and rural areas would subsequently be made closer. We will discuss the possibility in Sections 2 and 3.

In the urban production system, all built environments serve human needs, whereas infrastructure is the backbone of any economy (Zanabria Ruiz, 2015). TOD and ICT are the means for achieving SUD and the main actors for building the logistics and virtual communication network in the pursuit of digital-ruralism. As a potent sustainable urban planning tool, TOD is famous for its effectiveness in shaping the urban form and imposes a significant impact on enhancing the urban QOL (BOT, 2020). ICT acts as the catalyst by networking virtual connectivity for smart growth. TOD and ICT foster sustainable urbanization because they provide efficient communication and effective mobilization of labor forces and goods. For example, Al technology, driverless vehicles, online shopping platforms, solar plants, and wind farms can be facilitated and monitored by the $5 G$ network to increase aggregate value (productivity accumulated from different divisions of labor).

ICT is the key to value creation and competitive advantages, especially after labor, land capital, and overall productivity factors in a developed country. The faster the Internet access and the more comprehensive the coverage leads to the higher the human productivity. People worldwide can exchange intangible ideas and knowledge, financial activities, entertainment, and social activities in the digital world without time-space constraints. ICT facilitates the output generated from human capital, monetary capital, cultural context, and natural resources distributed through TOD networks more precisely and sustainably. The narrative of TOD and ICT's power on affecting $\mathrm{MHN}$, defined by the conceptual UxR development framework, has been unprecedentedly documented in the post-industrial society. The following sections will discuss and test the new development framework with a demand-side approach. 


\section{Research Design and Methodology}

This section analyses and justifies the proposed UxR development framework by proving ICT and TOD's roles in enhancing the critical sustainability-Uqol (well-being) indicators defined by the developing countries. Three objectives for accomplishing the task include: (1) to illustrate a well-being gap between the developing countries and developed countries through an Uqol survey; (2) to revise the classical MHN model into the indicatorbased MHN model (Figure 6) based on the findings from (Table 1); and (3) to illustrate TOD and ICT are related to the defined sustainability-Uqol indicators positively through a structural equation modeling (SEM: Figure 7) goodness-of-fit test.

The classical MHN theory is essential for developing the indicator-based MHN model (Figure 6) to construct the theoretical SEM for testing. The SEM is a relationship path of TOD and ICT measured by the well-being indicators (indicator-based MHN). First, we established the theoretical model (Figure 4-B) from the literature review and a sustainability-Uqol evaluation (Figure 4-A1 and 4-C1). Second, we conducted a confirmatory factor analysis (CFA) and SEM to test the strength of prediction recommended by (Anderson \& Gerbing, 1988; Williams \& Hazer, 1986), attempting to prove the association of the 11 observed well-being indicators under the two latent constructs (TOD and ICT). The research design prompts for initiating the proposed UxR frame- work: A + B (Figure 6) + C (Methodology: Table 1, Figure 7) = Output (Figure 8).

Wheeler (1996) argued that SUD is possible if mutual understanding and cooperation among the stakeholders, especially the city government and the residents. To understand the urban condition, evaluating subjective perceptions on the objective living environment is fundamental (Campbell, 1976; Low et al., 2017; Marans, 2014; Marans \& Stimson, 2011; Mukherjee, 1989; Sedaghatnia, Lamit, Ghahramanpouri, \& Mohamad, 2013; Veenhoven, 2000) and necessary for drafting the effective local development plans. More specifically, the Uqol evaluation is affected by the demographic attributes, and that these attributes are influenced by the objective living environment (Campbell, 1976; D'Acci, 2014; Marans \& Stimson, 2011). Therefore, we conducted a sustainability-Uqol survey to document the well-being disparities between developed and developing countries to state a need for livelihood improvement in the developing countries.

\subsection{Sustainability-Uqol Survey Design}

After defining the Uqol with SUD, TOD, ICT, MHN, and the digital-ruralism support in developing China, we asked: What is good Uqol and bad Uqol according to residents' needs? To drive for resilient development while improving livelihood, we conducted a sustainability-Uqol evaluation to learn about the wellbeing demands between the developing and developed

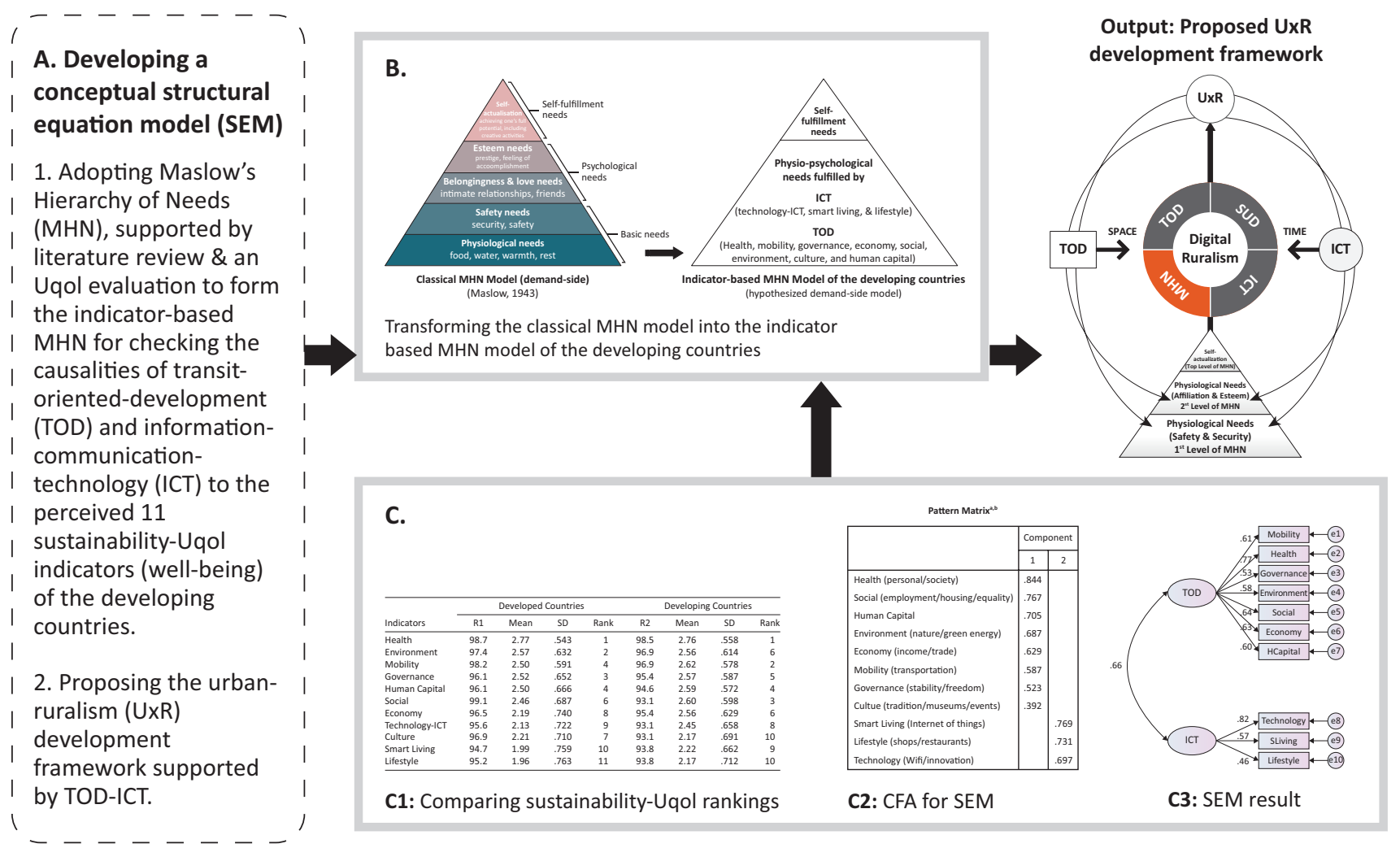

Figure 4. Research design. 
countries in the digital age. The Uqol questionnaire (https://forms.gle/CFG9HDiitZDenxs96) was designed by referring to the subjective-well-being questionnaire (GNH, 2015) with modification. A professional panel composed of Professors/scholars and PhD students discussed and tested the questionnaire who are the experts in sustainable urban planning, sociology, environmental, architecture, and design engineering from the Interuniversity Department of Regional and Urban Studies and Planning in the Politecnico di Torino, Italy twice. Convenient sampling was conducted via online and offline channels for six months in 2018-2019. Distribution channels include Facebook, WhatsApp, WeChat, emailing, and collaboration with a non-profit-organization.

\subsubsection{Demographic and Geographical Profile}

The sample total is 358 (64\% developed countries and $36 \%$ developing countries) from 47 countries. In Figure 5, female respondents (56\%) are more than male respondents (44\%). Age 26-35 occupies the highest portion (38\%) of the sample, followed by age 16-25 (20\%), 36-45 (17\%), 46-55 (14\%), and 56+ (11\%). 43\% are postgraduate, $29 \%$ are undergraduate, and $28 \%$ below undergraduate. In the professional group, $36 \%$ are students, $49 \%$ are employed, and $15 \%$ are either retired or unemployed. The sample profile reflects a young diversified, and welleducated group of representation, which would serve as the applicable sample to advise the future SUD requests. The wide coverage of countries presents a comprehensive study, but to collect more regional data in-depth investigation is still needed. In the future, we would like to invite the concerned researchers and institutions to collaborate in conducting more regional surveys so that the stakeholders can review the different pieces of a pic-

Percentage frequency

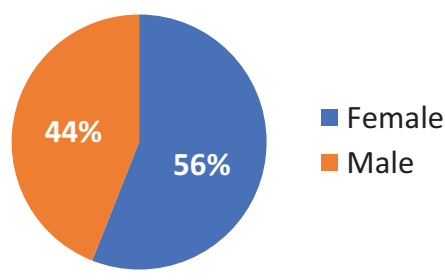

Percentage frequency (education)

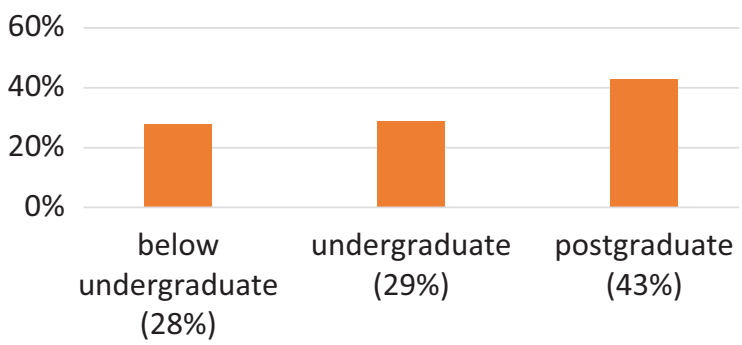

Figure 5. Demographic profile. ture without puzzling. We have the questionnaire interpreted into French, Russian, Arabic, Portuguese, Spanish, Italian, Indonesian, and Chinese.

\subsubsection{Comparison of Mean Score Rankings: A Demand-Side Evaluation}

The 11 sustainability-Uqol criteria embed the four components of TOD, ICT, MHN, and SUD identified by the extant literature and supported by China's digital ruralism accomplishment. The theme of 'sustainability enhances urban livelihoods' was adopted to select the 11 indicators out of 72 indicators from the relevant sustainability-Uqol indices: (CIMI, 2018; GPCI, 2018; MQCR, 2018; SCI, 2018; SCMI, 2017; SPI, 2018; WHR, 2019), which had been verified in a panel discussion. IBM SPSS Statistics 20 English version software was hired to run the raw data collected. The main question presented to the international respondents was: "Which factors/indicators are important in your IDEAL living environment?" in a 3-point Likert scale set ( 1 = least important to $3=$ most important). We conducted Descriptive Statistics, Cronbach's Alpha reliability test, normality test, and Mean Score test. The techniques for running the data have been practiced and illustrated by (Kingsford \& Chan, 2019). The Cronbach's alpha reliability test (Likert scale bigger than 0.7 ) justified that the chosen scale was suitable, the data collection instrument was strongly reliable, and the responses were consistent with the survey (Shen, Lu, Peng, \& Jiang, 2011; SPSS, 2006). We set the mean score threshold at $1.5(\mu=1.5)$, which benchmarked any sustainability-Uqol criteria with a mean score $\mu_{\mathrm{a}}>1.5$ as an indication of the significance of the identified indicators listed. The test result shows that the null hypothesis $(\mu=1.5)$ was rejected with a $p$-value:

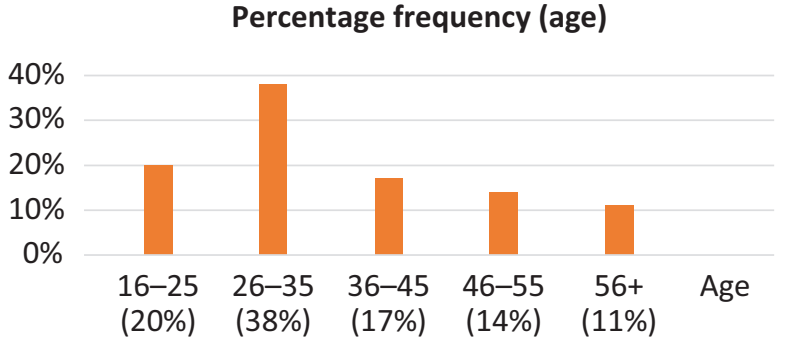

Percentage frequency (profession)

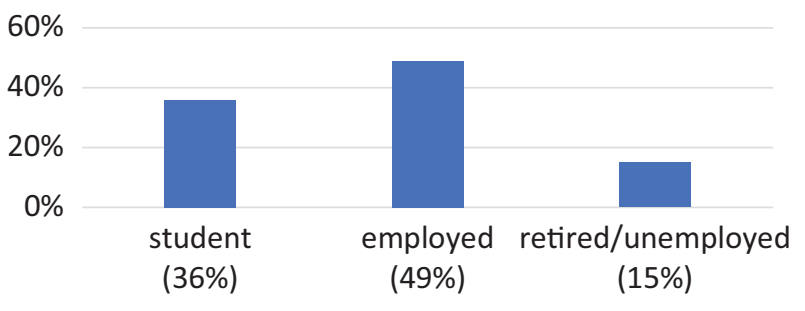


$0.000<0.05$ and a frequency rate of over $90 \%$. The 11 sustainability-Uqol (well-being) indicators were validated. It allowed the CFA and SEM for a model-fit test (Gokdemir \& Dumludag, 2011; Sullivan \& Artino, 2013).

Table 1 displays three sets of ranking characteristics. First, the top-ranking of health unanimously signifies that urban development should be human-oriented. Second, a similar ranking section composes human capital, technology-ICT, smart living, and lifestyle, showing that those critical sustainability-Uqol indicators are the respondents' universal well-being demand from both the developing and developed regions. Third, a more significant ranking division showing the well-being gaps in the environment, mobility, governance, social, economy, and culture exist between the developing and developed countries. The lower the ranking number shows, the stronger the well-being demand perceiving by the respondents. The developing countries perceived the environment, governance, and culture (sixth, fifth, and tenth) as less critical than developed countries (second, third, and seventh). The developing countries ranked mobility, social and economic demand (second, third, and sixth) relatively stronger than the developed countries (fourth, sixth, and eighth), indicating a wellbeing gap of mobility, socioeconomic development disadvantage to the developing countries due to the different urban development stages (Lam, 2021). To Ali and Nsairat (2009), the developing countries often valued economic and social development over environmental sustainability to the developed countries. Worth noting, they both ranked economy relatively low at sixth and eighth out of 11 indicators, implying that the economy-led development policy might need a modification. In this case, developed countries are recognized as urban, and developing countries are rural (China is an industrialized country facing the same urban issues as the developed countries, and its rural area is like the developing countries in terms of development). The well-being gaps between them (developed-urban vs. developing-rural) can be narrowed by adopting digitalruralism as China's case, rationalizing the UxR concept. Thus, the validated 11 sustainability-Uqol indicators can provide the information for constructing the indicatorbased MHN model.

\subsection{Constructing the Indicator-Based MHN Theoretical Model}

This section transforms the classical MHN into the more time-sensitive and indicator-based model for undergoing SEM examination. According to the classical MHN theory, human needs categorizing by $\mathrm{MHN}$ are satisfied through activities fulfilled in different life domains, including health, residential/food/safety, work, and home, leisure, education, social, friendship/family/love, and spiritual (Shek \& Lee, 2007; Sirgy \& Lee, 2016). MHN provides a core principle for categorizing and analyzing residents' needs to identify life satisfaction (Harifah, Nasrudin, \& Foo, 2014; Maslow \& Boeree, 2006; Renne, Curtis, \& Bertolini, 2009). On the one hand, developing countries appeal to fulfill physiological needs of socioeconomic-driven offerings such as health care, convenient transportation, employment, welfare, infrastructure development, and a well-performed corruptionfree government (Mukherjee, 1989). On the other hand, Kahneman, Diener, and Schwarz (1999) suggested that environmental-cultural context and self-identity sit at MHN's psychological level, which is often desired by the developed countries. In the digital period, the identified well-being demand (Table 1) expected by the develop-

Table 1. Comparison of mean score rankings of sustainability-Uqol.

\begin{tabular}{lcccccccc}
\hline & \multicolumn{3}{c}{ Developed Countries } & \multicolumn{3}{c}{ Developing Countries } \\
\cline { 2 - 8 } Indicators & R1 & Mean & SD & Rank & R2 & Mean & SD & Rank \\
\hline Health & 98.7 & 2.77 & .543 & 1 & 98.5 & 2.76 & .558 & 1 \\
Environment & 97.4 & 2.57 & .632 & 2 & 96.9 & 2.56 & .614 & 6 \\
Mobility & 98.2 & 2.50 & .591 & 4 & 96.9 & 2.62 & .578 & 2 \\
Governance & 96.1 & 2.52 & .652 & 3 & 95.4 & 2.57 & .587 & 5 \\
Human Capital & 96.1 & 2.50 & .666 & 4 & 94.6 & 2.59 & .572 & 4 \\
Social & 99.1 & 2.46 & .687 & 6 & 93.1 & 2.60 & .598 & 3 \\
Economy & 96.5 & 2.19 & .740 & 8 & 95.4 & 2.56 & .629 & 6 \\
Technology-ICT & 95.6 & 2.13 & .722 & 9 & 93.1 & 2.45 & .658 & 8 \\
Culture & 96.9 & 2.21 & .710 & 7 & 93.1 & 2.17 & .691 & 10 \\
Smart Living & 94.7 & 1.99 & .759 & 10 & 93.8 & 2.22 & .662 & 9 \\
Lifestyle & 95.2 & 1.96 & .763 & 11 & 93.8 & 2.17 & .712 & 10 \\
\hline
\end{tabular}

Notes: Total sample size: 358 (developed countries: 228; developing countries: 130) Respondent rate: R1 \& R2. Reliability test for the 11 indicators: Cronbach's Alpha (all countries $=.845$; developed countries $=.848$; developing countries $=.825$ ). P-value: $0<0.05$. Developed countries: Australia, Austria, Belgium, Bulgaria, Canada, Croatia, Czechia, Finland, France, Germany, Greece, Ireland, Italy, Japan, Latvia, Netherlands, Poland, Republic of Korea, Romania, Spain, Sweden, UK, and USA. Developing countries: Argentina, Azerbaijan, Bangladeshi, Benin, Brazil, China, Colombia, Egypt, Ethiopia, Ghana, India, Indonesia, Iran, Kazakhstan, Lebanon, Malaysia, Mexico, Morocco, Nigeria, Pakistan, Philippines, Russia, South Africa, and Sri Lanka. Source: UN (2014). 
ing countries are health, mobility, social, human capital, governance, environment, economy, technologyICT, smart living, culture, and lifestyle attaining to both MHN levels. As such, we revised the classical $\mathrm{MHN}$ into the indicator-based MHN model disregarding the hierarchical division with the modern wellbeing indicators. We claimed that TOD-ICT could fulfill the MHN's physio-psychological level and bridging the human-social-economic-environmental-digital gap between the urban and remote rural areas, advocated by the ICT implementation policies in Europe and digitalruralism in developing China. Figure 6 displays the contextual MHN's transformation to the indicator-based MHN model, which will be used for studying the causeeffect relationship of the sustainable-TOD-ICT to the observed MHN (well-being indicators).

\subsection{SEM}

SEM technique was adopted for validating the indicatorbased MHN model because it is an efficient and robust statistical technique to analyze a series of interrelationships and causal relationships among multiple observed variables and detect latent constructs simultaneously in a model. The hypothetical latent constructs TOD and ICT were identified from the literature and measured by the sustainability-Uqol criteria to form the SEM for testing its causality significance. There were two stages involving the reliability test of measurement model CFA and model fit test of SEM. In Figure 7, the Kaiser-Meyer-Olkin value is $0.818>0.5$ (Hair, 2019) and a significant probability of $0<0.05$ for the Barlett test of Sphericity (Shan, Le, \& Yiu, 2017), it means the matrix is correlated and factorable, not identity matrix. As the study was designed to inform developing countries' future urban development policy, the developing countries' data were used to undergo an SEM fittest. The developing countries' data were collected from $106>100$ respondents for five or fewer latent constructs is acceptable (Awang, 2012). The CFA result displays two significant factors: Eigenvalue $>1$ (Seo, Torabi, Blair, \& Ellis, 2004). It indicates that factor one consists of health, social, human capital, environment, economy, mobility, and governance, and factor two has technology, lifestyle, and smart living. The culture of factor one was dropped because $0.392<0.50$. The CFA result transformed the indicator-based MHN model into the hypothetical SEM.

We used Analysis of Moment Structures (AMOS vers. 20.0, IBM) to perform SEM goodness-of-fit test because it can run the non-normal data to examine the structural path coefficients for a robust estimation (Awang, 2012). Three hypotheses were designed to draw a causal path diagram (see Tables 2 and 3). Figure 7 illustrates the testing result of the hypothetical SEM:

H1: TOD has a significant positive relationship with health, governance, mobility, environment, social, economy, and human capital.

H2: ICT has a significant positive relationship with technology, lifestyle, and smart living.

\section{H3: TOD and ICT are correlated positively.}

The goodness-of-fit assessment derives from Chi-square/ $\mathrm{df}=1.532<5$, probability level $=0.000<.05$ (Marsh \& Hocevar, 1985), RMSEA $0.071<0.08$ (Browne \& Cudeck, 1992), GFI $0.91>0.90$ (Joreskog \& Sorbom, 1984), and CFI: $0.93>0.9$ considered a good fit (Baumgartner \& Homburg, 1996; Bentler, 1990).

All the tested factor loading were fit in the model with a score close to or between 0.5 to 0.8 . Hypotheses ( $\mathrm{H} 1$ and $\mathrm{H} 2)$ of ICT and TOD significantly impact the MHN model's defined physio-psychological level. All corresponding factor loads of the measurement are positive, stating that the ten observed variables are effective indicators for measuring TOD and ICT. In other words, TOD and ICT are the cause for affecting the ten indicators

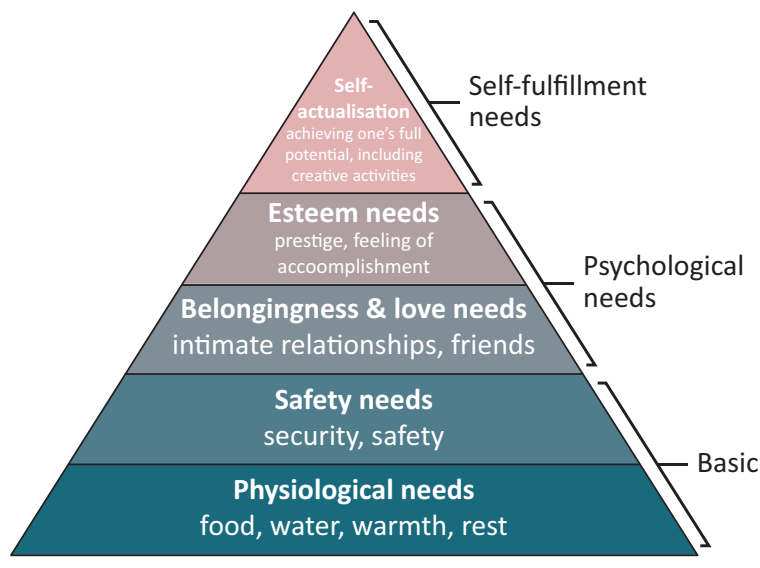

Classical MHN Model (demand-side) (Maslow, 1943)

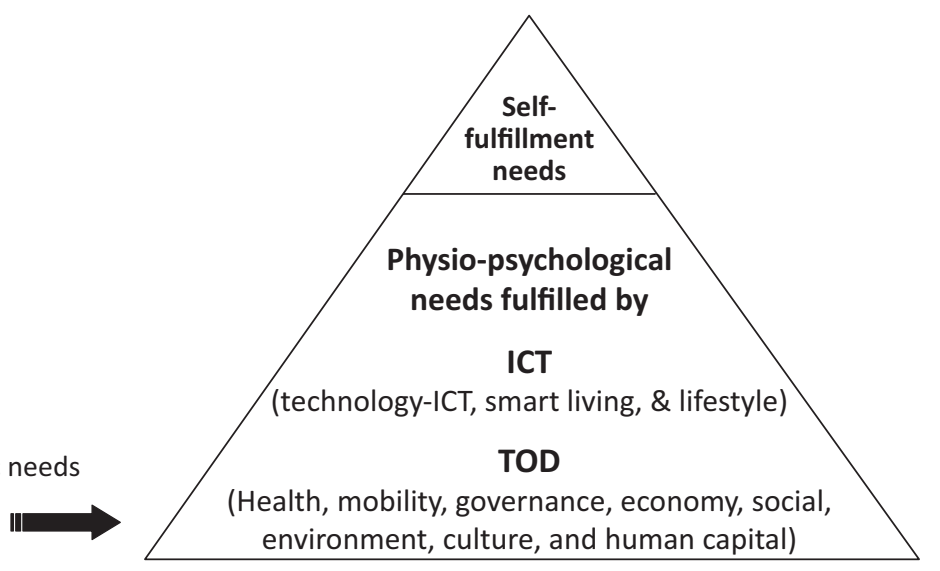

Indicator-based MHN Model of the developing countries (hypothesized demand-side model)

Figure 6. Transforming the classical MHN model into the indicator-based MHN model of the developing countries. 
Pattern Matrix ${ }^{\mathrm{a}, \mathrm{b}}$

\begin{tabular}{|l|c|c|}
\hline \multirow{2}{*}{} & \multicolumn{2}{|c|}{ Component } \\
\cline { 2 - 3 } & 1 & 2 \\
\hline Health (personal/society) & .844 & \\
Social (employment/housing/equality) & .767 & \\
Human Capital & .705 & \\
Environment (nature/green energy) & .687 & \\
Economy (income/trade) & .629 & \\
Mobility (transportation) & .587 & \\
Governance (stability/freedom) & .523 & \\
Cultue (tradition/museums/events) & .392 & \\
Smart Living (Internet of things) & & .769 \\
Lifestyle (shops/restaurants) & & .731 \\
Technology (Wifi/innovation) & & .697 \\
\hline
\end{tabular}

Extraction Method: Principal Component Analysis. Rotation Method: Oblimin with Kaiser Normalization.

a. Rotation converged in 4 iterations.

b. Developing countries are used in the analysis phase.

Figure 7. Results of CFA and SEM.

statistically significant with $\mathrm{p}$-value $=0<0.05$. TOD plays a significant role in affecting health (0.77), social (0.64), economy (0.63), mobility (0.61), human capital (0.60), environment (0.58), and governance $(0.53)$ which, while ICT contributes significant to technology (0.82), smart liv-

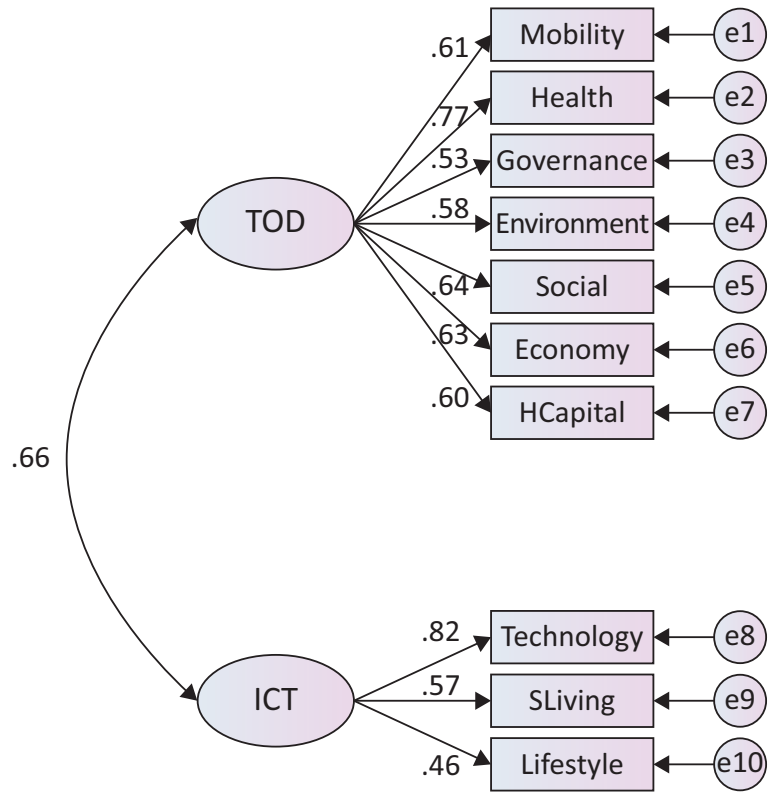

Fitness Indexes:

ChiSq $=52.095 ; \mathrm{df}=34 ; \mathrm{ChiSq} / \mathrm{df}=1.532$

$\mathrm{GFI}=0.914 ; \mathrm{AGFI}=0.862 ; \mathrm{CFI}=0.934 ; \mathrm{RMSEA}=0.071$

ing (0.57), and lifestyle (0.46). H3 is supported by a correlation $0.66<0.85$ (Awang, 2012). The acceptance of the indicator-based MHN model was justified by the significant positive relationships between the two latent factors to the observed well-being indicators.

Table 2. Results of SEM testing.

\begin{tabular}{lcccc}
\hline Model-Fit category & Name of index & Level of acceptance & Index Value & Tested Result \\
\hline Parsimonious fit & Chi-sq/df & Chi-sq/df $<5$ & $1.532<5$ & good \\
Absolute fit & RMSEA & RMSEA $<0.08$ & $0.071<0.08$ & good \\
& GFI & Rang $0.05-0.1$ is acceptable & & \\
Incremental fit & CFI & GFI $>0.90$ & $0.91>0.90$ & good \\
\hline
\end{tabular}

Notes: * = Goodness-of-fit indices of SEM suggested by Awang (2012). Critical Number is 98, sample size is $106>98$; bootstrapping: 2.000 times.

Table 3. Results of hypothesis testing for the respected path.

\begin{tabular}{lccc}
\hline Hypothesis statement of path analysis & Estimate & P-value & Results on hypothesis \\
\hline $\begin{array}{l}\text { H1: TOD has a significant positive relationship with health, } \\
\text { governance, mobility, environment, social, economy, } \\
\text { and human capital. }\end{array}$ & $0.53-0.77$ & 0.00 & supported \\
H2: ICT has a significant positive relationship with technology, & $0.46-0.82$ & 0.00 & supported \\
lifestyle, and smart living. & & 0.66 & 0.00 \\
H3: TOD and ICT are correlated positively. & & supported \\
\hline
\end{tabular}


Although SEM is called causal modeling, the conclusion should come from the research design (Figure 4) rather than a statistical model. The above path diagram of the fitted SEM and the indicator-based MHN model proves that $\mathrm{MHN}=\mathrm{TOD}+\mathrm{ICT}$, which means TOD and ICT, can theoretically contribute to physiopsychological needs listed in the revised MHN model. Together with the literature, the findings of mean score ranking comparison (developed-urban vs. developingrural), the indicator-based MHN model, and the SEM testing result significantly validated the conceptual UxR development framework (Figure 8). Whereas the human habitat is a complex-adaptive system evolved in hierarchical order exhibited by villages, towns, cities, countries, and the world, we need to evaluate the micro-entity to learn and predict the next inline macro reality for understanding urban development. Thus, more empirical studies from the supply side are needed to strengthen the practicality of the new development framework.

\section{Discussion and the UxR Development Framework}

In Section 2, the quantitative justification shows that TOD-ICT could theoretically contribute to physiopsychological well-being enhancement, regenerating the classical MHN on the ordering of human needs. Figure 7 shows TOD and ICT's causal flow to the ten observed well-being indicators and their correlational relationship from the demand-side perspective. SEM validated the indicator-based MHN model presenting the rationale of the UxR development framework.

From the European perspective, mirrored by the illustration of 'eclectic atlas' and the 'diffuse city' introduced by Stefano Boeri and Francesco Indovina, respectively, the observed urban phenomena in the European landscape not only a visual presentation, but also reveals the historical context shaped by human behavior and demand. A recognization of human habitation can be networked by an array of satellite towns disregarding geographical constraints and implying the UxR development path's possibility. The planetary urbanization experiences of developed Europe play like an urban development lesson for developing countries. Indeed, the EU has designed the workable blueprint for future urbanrural sustainable development. China's success in learning from the EU proves that the EU's digital development approach is worth implementation. It made the belief that whoever can access broadband Internet connectivity within rural areas can achieve economic and cultural progress, and the mix of endogenous and exogenous forces interacting at the local level encourages urbanites to move into the rural area (Roberts, Beel, Philip, \& Townsend, 2017). As such, a new concept of urbanrural development should be introduced to harness the relationship between the urban establishment and the vast rural potential of growth to realize sustainable goals

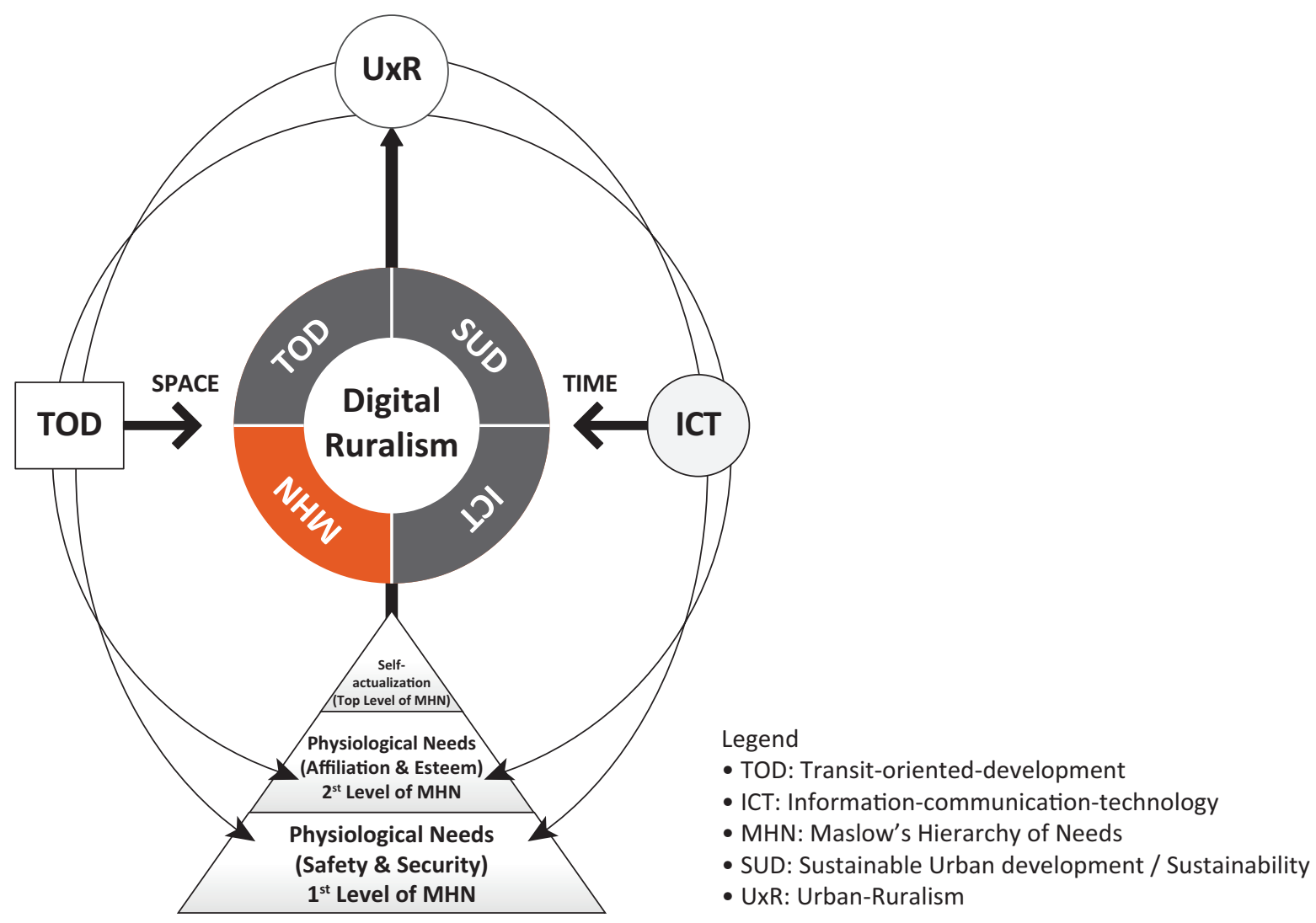

Figure 8. Proposed UxR development framework. 
and enhance human well-being. It reassures the new sustainable development path for developing and preserving the future urban-rural landscape in developing countries.

\section{Conclusion}

In the post-industrial society, where TOD-ICT advancement (physical and virtual connectivity) allows many activities to be done almost anywhere, location choices are increasingly free of geographical limits empowered by digitalization. By referring to the action-based ICT eEurope 2005 and i2010 development frameworks and China's digital-ruralism, the social, economic, environmental, cultural, and digital divide between the urban and rural areas (developed-urban and developing-rural) can be narrowed by ICT. With the maturity of digital technology, urbanization will shift back to the countryside, where the smart living mode is defined by e-employment for self-reliance, the Internet of things, e-health, e-education, e-commerce, e-entertainment, and e-chat.

The demand-side research illustrates that TOD-ICT contributes to health, mobility, governance, environment, social, economy, human capital, technology-ICT, smart living, and lifestyle without location constraints in developing countries. It provides new knowledge for modernizing the classical MHN into the indicator-based MHN. In such a new theory, the UxR development framework can fulfill the contemporary MHN's physiopsychological needs almost instantaneously. Likewise, it envisages that the past and present of the developed countries might not be necessary to be the future of developing countries.

Our study concluded that the economy-led urbanization path is critical for initiating smart growth in developing countries; however, the development process should be guided by understanding and providing for the human needs while optimizing the sustainability goals. By adopting sustainable development strategies such as TOD-ICT, the application can develop local capacity to access external markets and internal resources (nature and human resources) to confront accessibilitysocioeconomic inequalities within places. It highlights the harmony between urban and rural development, energizing interaction between cities, towns, and rural areas to the local, national and global marketplaces, merging the development gaps divided by multi-scalar geography. In future development, more empirical studies applying big data cloud well-being ratings and mapping should be conducted so that the new framework can stand the challenges of time and space. The enhanced economy-led urbanization development path would be one of many choices considered by the developing countries' policymakers and urban planners because it will help prevent them from running into the same historical setbacks as the developed countries while securing resilient development.

\section{Acknowledgments}

Thank you to the Politecnico di Torino: Prof. Patrizia Lombardi, Prof. Isabella Lami, Dr. Osman Arrobbio, Dr. Francesca Abastante, Dr. Angioletta Voghera, Dr. Giulia Sonetti, Dr. Sara Torabi, and their PhD students for pilot testing the survey forms before bulk distribution. Special thanks go to Miss Sara Cravero for interpreting the survey into Italian, and Mrs. Tecla Zaia (President), and Mr. Sanjay Sankar (Manager) from the AlloggiAmiNGO for distributing and collecting the survey forms.

\section{Conflict of Interests}

The authors declare no conflict of interest.

\section{References}

Ali, H., \& Nsairat, S. F. (2009). Developing a green building assessment tool for developing countries: Case of Jordan. Building and Environment, 44, 1053-1064.

Anderson, C., \& Gerbing, W. (1988). Structural equation modelling in practice. Psychological Bulletin, 103(3), 411-423. https://doi.org/10.1037/0033-2909.103.3. 411

Awang, Z. (2012). A handbook on structural equation modelling using AMOS. Malaysia: Universiti Technologi MARA Press.

Ballas, D., \& Tranmer, M. (2011). Happy people or happy places? A multilevel modelling approach to the analysis of happiness and well-being. International Regional Science Review, 35(1), 70-102. https://doi. org/10.1177/0160017611403737

Baumgartner, H., \& Homburg, C. (1996). Applications of structural equation modelling in marketing and consumer research: A review. International journal of Research in Marketing, 13(2), 139-161.

Bentler, P. M. (1990). Comparative fit indexes in structural models. Psychological Bulletin, 107, 238-246.

BOT. (2020). Benefits of TOD. TOD. Retrieved from http:// www.tod.org/home.html

Browne, M. W., \& Cudeck, R. (1992). Alternative ways of assessing model fit. Sociological Methods \& Research, 21(2), 230-258.

Campbell, A. (1976). Subjective measures of well-being. American Psychologist, 31(2), 117-124.

CIMI. (2018). IESE cities in motion index 2018. Cities in Motion. Retrieved from https://blog.iese.edu/ cities-challenges-and-management/2018/05/23/ iese-cities-in-motion-index-2018

D’Acci, L. (2014). Monetary, subjective and quantitative approaches to assess urban quality of life and pleasantness in cities (hedonic price, willingness-to-pay, positional value, life satisfaction, isobenefit lines). Social Indicators Research, 115(2), 531-559.

Freeman, C. (1996). The two-edged nature of technical change: Employment and unemployment. In W. H. Dutton (Ed.), Information and communication tech- 
nologies: Visions and realities (pp. 19-36). Oxford: Oxford University Press.

From nobody to somebody: China's high-speed rail in numbers. (2020, October 1). China Global Television Network. Retrieved from https://news.cgtn. com/news/2020-10-01/From-nobody-to-somebodyChina-s-high-speed-rail-in-numbers-Udm6mE3qqA/ index.html

GNH. (2015). The third gross national happiness survey questionnaire: A compass towards a just and harmonious society. Thimphu: Centre for Bhutan Studies and GNH Research.

Gokdemir, O., \& Dumludag, D. (2011). Subjective wellbeing among ethnic minorities: the Dutch case. Munich: Munich University Library.

GPCl. (2018). Global power city index 2018. Institute for Urban Strategies: The Mori Memorial Foundation. Retrieved from http://mori-m-foundation.or. jp/english/ius2/gpci2/index.shtml

Hair, J. F. (2019). Multivariate data analysis (8th ed.). London: Pearson Education Limited.

Harifah, M. N., Nasrudin, N., \& Foo, J. (2014). Determinants of Customer Satisfaction of Service Quality: City Bus Service in Kota Kinabalu, Malaysia. Procedia: Social and Behavioral Sciences, 153. https://doi.org/ 10.1016/j.sbspro.2014.10.092

Helliwell, J. F., Huang, H., \& Wang, S. (2019). Chapter 2: The social foundations of world happiness. New York, NY: UN Sustainable Development Solutions Network. Retrieved from https://s3.amazonaws.com/ happiness-report/2019/WHR19_Ch2.pdf

Joreskog, K. G., \& Sorbom, D. (1984). LISREL VI: User's guide. Mooresville, IN: Scientific Software.

Kahneman, D., Diener, E., \& Schwarz, N. (1999). Wellbeing: The foundations of hedonic psychology. New York, NY: Russell Sage Foundation.

Kingsford, O. E., \& Chan, A. P. C. (2019). Barriers affecting effective application of anticorruption measures in infrastructure projects: Disparities between developed and developing countries. Journal of Management in Engineering, 35(1). https://doi.org/10.1061/ (asce)me.1943-5479.0000667

Lam, S. (2021). Understanding and evaluating urban quality of life (Uqol) for enhancing sustainable urban development: A dual-complex-adpativesystem (U2-CAS) (Unpublished doctoral dissertation). The Hong Kong Polytechnic University, Hung Hom, Hong Kong.

Low, C.-T., Stimson, R., Chen, S., Cerin, E., Wong, P. P.-Y., \& Lai, P.-C. (2017). Personal and neighborhood indicators of quality of urban life: A case study of Hong Kong. Social Indicators Research, 136(2), 751-773. https://doi.org/10.1007/s11205-017-1579-3

Marans, R. W. (2014). Quality of urban life and environmental sustainability studies: Future linkage opportunities. Habitat International, 45, 47-52.

Marans, R. W., \& Stimson, R. (2011). An overview of quality of urban life. In R. Marans \& R. Stimson (Eds.),
Investigating quality of urban life: Theory, methods, and empirical research (Vol. 45, pp. 1-29). Cham: Springer Science.

Marsh, H. W., \& Hocevar, D. (1985). Application of confirmatory factor analysis to the study of self-concept: First-and higher order factor models and their invariance across groups. Psychological Bulletin, 97(3), 562-582.

Maslow, A. H. (1943). A theory of human motivation. Psychological Review, 50(4), 370-396. https://doi.org/ 10.1037/h0054346

Maslow, A. H., \& Boeree, G. (2006). Abraham Maslow (1908-1960): Personality theories. Shippensburg, PA: Shippensburg University.

MQCR. (2018). Mercer's QOL city ranking 2018. Mercer. Retrieved from https://www.mercer.com/ newsroom/2018-quality-of-living-survey.html

Mukherjee, R. (1989). The quality of life: Valuation in social research (Vol. 1). New Delhi: Sage.

Park, S. (2017). Digital inequalities in rural Australia: A double jeopardy of remoteness and social exclusion. Journal of Rural Studies, 54, 399-407.

Qiang, C. Z. W., Rossotto, C. M., \& Kimura, K. (2009). Economic impacts of broadband. In World Bank (Ed.), Information and communications for development 2009: Extending reach and increasing impact (pp. 35-50). Washington, DC: World Bank.

Renne, J., Curtis, C., \& Bertolini, L. (2009). Measuring the success of transit-oriented development. In C. Curtis (Ed.), Transit oriented development: Making it happen (pp. 241-255). London: Taylor \& Francis.

Roberts, E., Beel, D., Philip, L., \& Townsend, L. (2017). Rural resilience in a digital society: Editorial. Journal of Rural Studies, 54, 355-359. https://doi.org/ 10.1016/j.jrurstud.2017.06.010

Rondinelli, D. (1983). Towns and small cities in developing countries. Geographical Review, 73(4), 379-395.

SCl. (2018). Sustainable cities index 2018. Arcadis. Retrieved from https://www.arcadis.com/en/ united-states/our-perspectives/sustainable-citiesindex-2018/united-states

SCMI. (2017). Sustainable cities mobility index 2017. Arcadis. Retrieved from https://www.arcadis.com/ en/global/our-perspectives/sustainable-citiesmobility-index-2017

Sedaghatnia, S., Lamit, H., Ghahramanpouri, A., \& Mohamad, S. B. (2013). An evaluation of residents' quality of life through neighborhood satisfaction in Malaysia. Environmental Management and Sustainable Development, 2(1). https://doi.org/10.5296/ emsd.v2i1.3254

Seo, D., Torabi, M., Blair, E. H., \& Ellis, N. T. (2004). A crossvalidation of safety climate scale using confirmatory factor analytic approach. Journal of Safety Research, 35(4), 427-45.

Shan, M., Le, Y., \& Yiu, K. T. W. (2017). Investigating the underlying factors of corruption in the public construction sector: Evidence from China. Science and 
Engineering Ethics, 23, 1643-1666. https://doi.org/ 10.1007/s11948-016-9865-z

Shek, D. T., \& Lee, B. M. (2007). A comprehensive review of quality of life (Skevington) research in Hong Kong. Scientific World Journal, 7, 1222-1229.

Shen, L. Y., Lu, W. S., Peng, Y., \& Jiang, S. J. (2011). Critical assessment indicators for measuring benefits of rural infrastructure investment in China. Journal of Infrastructure Systems, 17(4), 176-183.

Sirgy, M. J., \& Lee, D. J. (2016). Work-life balance: A quality-of-life model. Applied Research in Quality Life, 11(4), 1059-1082.

SPI. (2018). Social progress index 2018. The Social Progress Imperative. Retrieved from https://www. socialprogress.org

SPSS. (2006). SPSS 15.0 for Windows brief guide. Englewood Cliffs, NJ: SPSS Inc.

Statistical Report. (2017). The 40th statistical report on Internet development in China. Beijing: China Internet Network Information Centre. Retrieved from https://cnnic.com.cn/IDR/ReportDownloads/ 201807/P020180711387563090220.pdf

Statistical Report. (2020). The 45th statistical report on Internet development in China. Beijing: China Internet Network Information Centre. Retrieved from http://cnnic.com.cn/IDR/ReportDownloads/ 202008/P020200827549953874912.pdf

Sullivan, G. M., \& Artino, A. R., Jr. (2013). Analyzing and interpreting data from likert-type scales. Journal of Graduate Medical Education, 5(4), 541-542. https://
doi.org/10.4300/JGME-5-4-18

UN. (2014). World economic situations and prospects 2014: Country classification. New York, NY: UN. Retrieved from https://www.un.org/en/ development/desa/policy/wesp/wesp_current/ 2014wesp_country_classification.pdf

UNDP. (n.d.). 2030 agenda of the United Nations Development Program. UNDP. Retrieved from https://www.undp.org/content/undp/en/home/ 2030-agenda-for-sustainable-development.html

Veenhoven, R. (2000). The four qualities of life. Journal of Happiness Studies, 1(1), 1-39. https://doi.org/ 10.1023/A:1010072010360

Wheeler, S. (1996). Sustainable urban development: A literature review and analysis. Institute of Urban and Regional Developemnt. Berkeley, CA: University of California at Berkeley.

WHR. (2019). World happiness report 2015-2019. Sustainable Development Solutions Network. Retrieved from https://worldhappiness.report/archive/

Williams, L. J., \& Hazer, J. T. (1986). Antecedents and consequences of satisfaction and commitment in turnover models: A reanalysis using latent variable structural equation methods. Journal of Applied Psychology, 71(2), 219-231.

Zanabria Ruiz, L. (2015). Qualitative studies of young people's quality of life in urban and rural areas. In G. Tonon (Eds.), Qualitative studies in quality of life (pp. 149-178). Cham: Springer. https://doi.org/10.1007/ 978-3-319-13779-7_8

\section{About the Authors}

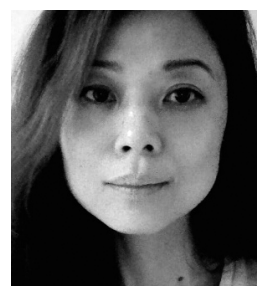

Schuman Lam graduated with a BSc in Marketing from the University of Illinois at Chicago, an MSc, and a PhD in Sustainable Urban Development from the Hong Kong Polytechnic University. The winner of the CIB Sebestyén Future Leaders Award 2016 for 'Setting up a Virtual CIB Community for Integrated Design \& Delivery Solutions (IDDS).' Her research focuses on digital urban-rural development relating to transit-oriented-development and information-communication-technology, sustainability, quality of life evaluation, and development policymaking.

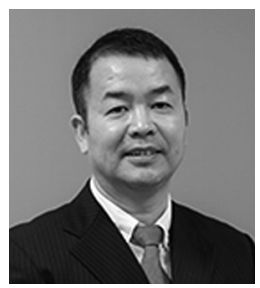

Heng Li graduated from Tongji University, lectured at the University of Sydney, James Cook University, and Monash University. He was a vivid Consultant for firms and governments in Australia, Hong Kong SAR and China before joining the Hong Kong Polytechnic University. He published two books and over 300 journal papers and concentrated on innovative research projects.

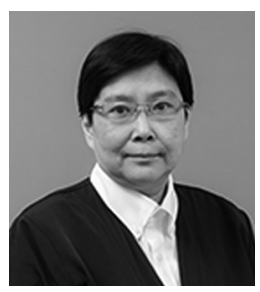

Ann T. W. Yu received a BSc degree in Building from the University of Brighton, UK, a MSc degree in Construction Management from Hong Kong, and a PhD from the Department of Building and Real Estate, The Hong Kong Polytechnic University, in 2007. She started her profession as an Assistant Architect in several architectural firms. She has published extensively in leading construction management journals. 